\title{
Genetic variant in fat mass and obesity-associated gene associated with type 2 diabetes risk in Han Chinese
}

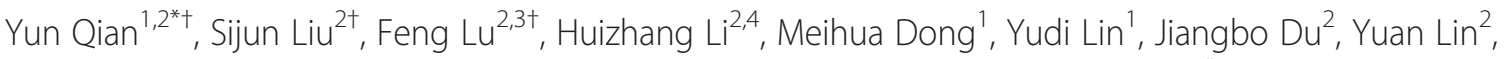 \\ Jianhang Gong ${ }^{2}$, Guangfu Jin ${ }^{2}$, Juncheng Dai ${ }^{2}$, Zhibin $\mathrm{Hu}^{2,5}$ and Hongbing Shen ${ }^{2,5^{*}}$
}

\begin{abstract}
Background: Genome-wide association study (GWAS) has identified that rs8050136 C/A polymorphism in fat mass and obesity-associated gene (FTO) was associated with the risk of type 2 diabetes (T2D) in Europeans. But this association was abolished after adjustment for body mass index (BMI), suggesting that the effect of rs8050136 on T2D risk might be mediated by BMI in Europeans. However, the findings in subsequent studies were inconsistent among Asian populations. To determine whether rs8050136 polymorphism in FTO is independently associated with the risk of T2D in Chinese, we conducted a case-control study with 2,925 T2D patients and 3,281 controls in Han Chinese.
\end{abstract}

Results: Logistic regression revealed that the $A$ allele of rs8050136 was significantly associated with an increased risk of T2D, independent of BMI (odds ratio $(\mathrm{OR})=1.17,95 \%$ confidence interval $(95 \% \mathrm{Cl})=1.03-1.32, \mathrm{p}=0.016)$. Meta-analysis containing 10 reported studies and our data with a total of 15,819 cases and 18,314 controls further confirmed the association between rs8050136 polymorphism and T2D risk in East Asians $(\mathrm{OR}=1.13,95 \% \mathrm{Cl}=1.07-1.19)$.

Conclusions: Our findings indicate that the genetic variant in FTO may contribute to T2D risk in Han Chinese and rs8050136 polymorphism may be a genetic marker for T2D susceptibility.

Keywords: Fat mass and obesity-associated Gene, Genome-wide association study, Genetic susceptibility, Single nucleotide polymorphism, Type 2 diabetes

\section{Background}

Type 2 diabetes (T2D) is a major global health problem with an increasing prevalence over the world [1]. More than $60 \%$ of the world's diabetes patients will be Asians in 2025 [2]. In China, it has become an epidemic concern due to the western lifestyle [3]. Although the etiology of T2D has not been well elucidated, genetic and environmental factors are considered to be involved in its development [4].

\footnotetext{
*Correspondence: wxqianyun111@sina.com; hbshen@njmu.edu.cn

${ }^{\dagger}$ Equal contributors

'Department of Chronic Non-communicable Disease Control, Wuxi Center for Disease Control and Prevention, Wuxi, China

${ }^{2}$ Department of Epidemiology and Biostatistics, MOE Key Laboratory of Modern Toxicology, School of Public Health, Nanjing Medical University, Nanjing, China

Full list of author information is available at the end of the article
}

In 2007, genome-wide association studies (GWAS) firstly reported that single nucleotide polymorphism (SNP) rs8050136 in fat mass and obesity-associated gene (FTO) was associated with the risk of T2D in European populations [5,6]. However, this association was not significant after adjustment for body mass index (BMI). Another GWAS identified SNP rs9939609 in FTO as strongly associated with both BMI and obesity in Europeans [7]. Based on the public HapMap SNP database, rs8050136 and rs9939609 were in the perfect linkage disequilibrium (LD) $\left(r^{2}=1\right)$. Therefore, it is suggested that the effect of rs8050136 or rs9939609 on T2D risk may be mediated through a primary effect on obesity in European populations.

Following the initial reports in populations of European descent, Horikoshi et al. found that rs8050136 was also associated with T2D risk in a Japanese population, however,

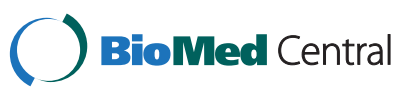


which was independent of BMI [8]. In contrast, $\mathrm{Ng}$ et al. did not find a significant association in Hongkong and Korean populations $(\mathrm{OR}=1.09,95 \% \mathrm{CI}=0.97-1.23)$ [9]. Among Chinese populations, the association between rs8050136 and T2D risk failed to be replicated in Hu's study [10]; however, $\mathrm{Han}$ et al. detected a positive association in another Chinese Han population [11]. To determine whether rs8050136 polymorphism in FTO is independently associated with the risk of T2D, we conducted a case-control study with 2,925 T2D cases and 3,281 controls in Han Chinese. In addition, we also undertook a systematic meta-analysis including 15,819 cases and 18,314 controls to assess the association between this FTO polymorphism and T2D risk in East Asians.

\section{Results}

The distributions of demographic and selected clinical characteristics of 2,925 T2D cases and 3,281 controls were summarized in (Additional file 1: Table S1). No significant differences were observed in the distributions of sex, smoking and drinking status. Type 2 diabetes cases were older than controls and had significantly higher levels of BMI, fasting blood glucose (FBG), triglyceride (TG), total cholesterol (TC), blood pressure and significantly lower level of high-density lipoprotein cholesterol (HDL-C). The genotype distribution of rs8050136 in FTO and its association with T2D risk between the T2D cases and controls were shown in Table 1 . The observed genotype frequencies for rs8050136 were in Hardy-Weinberg equilibrium (HWE) in the controls $(\mathrm{p}=0.941)$. Significant differences of genotype distribution between the T2D cases and controls were observed for rs8050136 in the dominant model (crude OR $=1.30,95 \% \mathrm{CI}=1.15-1.46$, $\mathrm{p}=3.0 \times 10^{-5}$ ) and the additive model (crude OR $=1.27$, $\left.95 \% \mathrm{CI}=1.13-1.41, \mathrm{p}=3.8 \times 10^{-5}\right)$. With the adjustment for age, sex and BMI in the logistic regression model, rs8050136 CA/AA genotypes were associated with a significantly increased risk of T2D (OR $=1.19,95 \%$ $\mathrm{CI}=1.04-1.37, \mathrm{p}=0.011$ ), as compared with $C C$ genotype. Similar association was also observed in the additive model (adjusted $\mathrm{OR}=1.17,95 \% \mathrm{CI}=1.03-1.32$, $\mathrm{p}=0.016)$.
We then conducted the stratified analyses by age, sex and BMI. As shown in Table 2, the associations between rs8050136 polymorphism and T2D risk were also evident in the groups of elderly subjects (age > 56 years: $\mathrm{OR}=1.24,95 \% \mathrm{CI}=1.05-1.46, \mathrm{p}=0.010)$, female subjects $(\mathrm{OR}=1.20,95 \% \mathrm{CI}=1.02-1.40, \mathrm{p}=0.025)$ and those with normal weight $\left(\mathrm{BMI}<24 \mathrm{~kg} / \mathrm{m}^{2}\right.$ : $\mathrm{OR}=1.25$, $95 \% \mathrm{CI}=1.07-1.46, \mathrm{p}=0.005)$. No heterogeneity was observed among these subgroups.

A total of 10 published studies on the association between rs8050136 polymorphism and T2D risk in East Asian populations were summarized in (Additional file 2: Table S2) [8-17]. These 10 studies, together with our present study, were included in the meta-analysis. Overall meta-analysis results revealed that rs8050136 A allele was associated with an increased T2D risk in East Asians $(\mathrm{OR}=1.13,95 \% \mathrm{CI}=1.07-1.19$, Figure 1$)$. Further meta-analysis also confirmed the association with T2D risk in Chinese Hans (OR $=1.16,95 \%$ $\mathrm{CI}=1.08-1.23$ ) (Additional file 3: Figure S1). No obvious heterogeneity was observed between the selected studies (heterogeneity $\mathrm{p}=0.430$ and $\mathrm{I}^{2}=1.2 \%$ for East Asians; heterogeneity $\mathrm{p}=0.569$ and $\mathrm{I}^{2}=0.0 \%$ for Chinese Hans). Funnel plot and Egger's test were used to address the potential publication bias and no significant publication bias was found $(t=-0.71, p=0.495$ for East Asians, Figure 2; $\mathrm{t}=-0.53, \mathrm{p}=0.617$ for Chinese Hans, Additional file 4: Figure S2).

\section{Discussion}

In this study, we investigated the association of rs 8050 136 polymorphism in FTO with T2D risk in Han Chinese. We found that rs8050136 A allele was significantly associated with an increased T2D risk in Han Chinese, which was further supported by a meta-analysis containing 10 reported studies in East Asians and our present study.

Although a number of studies have investigated the association between FTO rs8050136 polymorphism and T2D risk in Asian populations, the results were inconsistent. Horikoshi et al. reported a significant association $(\mathrm{OR}=1.22,95 \% \mathrm{CI}=1.03-1.46, \mathrm{p}=0.025)$ between rs8050136 and T2D risk in 864 cases and 864 controls

Table 1 The genotype distribution of rs8050136 and the association with type 2 diabetes risk in Han Chinese

\begin{tabular}{ccccccc}
\hline Genotype & Cases N (\%) & Controls N (\%) & OR (95\% Cl) & p-value & OR (95\% Cl) & p-value \\
\hline$C C$ & $2205(76.1)$ & $2625(80.5)$ & 1.00 & & $\mathbf{1 . 0 0}$ \\
$C A$ & $652(22.5)$ & $602(18.5)$ & $1.29(1.14-1.46)$ & $6.3 \times 10^{-5}$ & $\mathbf{1 . 2 0 ( 1 . 0 4 - 1 . 3 8 )}$ \\
$A A$ & $41(1.4)$ & $35(1.1)$ & $1.39(0.89-2.20)$ & 0.152 & $\mathbf{1 . 1 1 ( 0 . 6 6 - 1 . 8 7 )}$ & $\mathbf{0 . 6 8 7}$ \\
CA/AA & $693(23.9)$ & $637(19.5)$ & $1.30(1.15-1.46)$ & $3.0 \times 10^{-5}$ & $\mathbf{1 . 1 9 ( 1 . 0 4 - 1 . 3 7 )}$ & $\mathbf{0 . 0 1 1}$ \\
Additive & & & $1.27(1.13-1.41)$ & $3.8 \times 10^{-5}$ & $\mathbf{1 . 1 7}(\mathbf{1 . 0 3}-\mathbf{1 . 3 2})$ & $\mathbf{0 . 0 1 6}$
\end{tabular}

Genotype was successfully detected in 2,898 T2D cases and 3,262 controls. Odds ratios (95\% confidence intervals) and p-values were calculated in the logistic regression model. Results of adjustment for age, sex and body mass index are in bold. 
Table 2 The stratified analyses on the association between rs8050136 and the risk of type 2 diabetes

\begin{tabular}{|c|c|c|c|c|c|}
\hline Variables & Cases & Controls & OR $(95 \% \mathrm{Cl})$ & p-value & $\mathrm{p}$-value \\
\hline \multicolumn{6}{|l|}{ Age } \\
\hline$\leq 56$ & $863 / 246 / 15$ & 1165/260/17 & $1.07(0.88-1.30)$ & 0.484 & \multirow{2}{*}{0.258} \\
\hline$>56$ & $1341 / 406 / 26$ & $1460 / 342 / 18$ & $1.24(1.05-1.46)$ & 0.010 & \\
\hline \multicolumn{6}{|l|}{ Sex } \\
\hline females & $1382 / 400 / 28$ & $1641 / 372 / 23$ & $1.20(1.02-1.40)$ & 0.025 & \multirow{2}{*}{0.557} \\
\hline males & $823 / 252 / 13$ & $984 / 230 / 12$ & $1.11(0.90-1.36)$ & 0.350 & \\
\hline \multicolumn{6}{|l|}{ BMI } \\
\hline normal & $849 / 255 / 10$ & $2107 / 471 / 28$ & $1.25(1.07-1.46)$ & 0.005 & \multirow{3}{*}{0.663} \\
\hline overweight & $945 / 255 / 18$ & $438 / 111 / 5$ & $1.10(0.88-1.39)$ & 0.391 & \\
\hline obesity & $394 / 137 / 12$ & $74 / 20 / 2$ & $1.19(0.75-1.89)$ & 0.454 & \\
\hline
\end{tabular}

Listed are the counts of CC/CA/AA genotypes in T2D cases and controls. Odds ratios (95\% confidence intervals) and p-values were calculated in the logistic regression model with adjustment for age, sex and body mass index where appropriate. P-value in bold is for the heterogeneity test based on chi-squared based $\mathrm{Q}$ test.

in Japanese [8], which was supported by a larger study comprising 1,912 cases and 2,041 controls in a Han Chinese population $(\mathrm{OR}=1.22,95 \% \mathrm{CI}=1.05-1.41$, $\mathrm{p}=0.008$ ) [14]. However, Omori et al. were not able to replicate the association $(\mathrm{OR}=1.09,95 \% \mathrm{CI}=0.91-1.30$, $\mathrm{p}=0.350)$ in a case-control study with 1,630 T2D cases and 1,064 controls in Japanese [12]. In the present study, we observed the significant association between rs8050136 and T2D risk (OR $=1.17,95 \% \mathrm{CI}=1.03-1.32$, $\mathrm{p}=0.016)$ after adjustment for age, sex and BMI. The discrepancy of the association of rs8050136 with T2D risk in East Asians may be due to the relatively low frequency (minor allele frequencies $(\mathrm{MAFs})=0.12$ and 0.17 for Chinese and Japanese populations) leading to a low statistical power, as compared with the populations of European descent $(\mathrm{MAF}=0.45)$. Therefore, the meta- analysis conducted in this study may represent a powerful approach to clarify the relationship between rs8050136 and T2D risk by pooling 15,819 cases and 18,314 controls and confirm this association in East Asians.

Our study showed the $A$ allele of rs8050136 was significantly associated with an increased risk of T2D, independent of BMI. A recent meta-analysis including 96,551 East and South Asians reported that the minor allele for the rs9939609 FTO SNP (perfect LD with rs8050136) significantly increased the risk of both obesity and T2D, and the association between the FTO locus and risk of T2D remained significant after adjustment for BMI [18]. Interestingly, a recent meta-analysis of 41,504 Scandinavians revealed that the significant association for rs9939609 with the risk of T2D also remained after correction for BMI [19]. These results were not

\begin{tabular}{|c|c|c|c|}
\hline Study & Population & OR $(95 \% \mathrm{Cl})$ & Weight \% \\
\hline Horikoshi(2007) & Japanese & $1.22(1.03,1.46)$ & 8.34 \\
\hline $\mathrm{Ng}(2008)$ & HK \& Korean & $1.09(0.97,1.23)$ & 18.00 \\
\hline Li(2008) & Chinese & $0.91(0.71,1.16)$ & 4.21 \\
\hline Omori(2008) & Japanese & $1.09(0.91,1.30)$ & 7.98 \\
\hline Lee(2008) & Korean & $0.91(0.73,1.14)$ & 5.11 \\
\hline Song(2008) & Chinese & $1.22(0.73,2.04)$ & 0.96 \\
\hline $\mathrm{Hu}(2009)$ & Chinese & $1.13(0.98,1.29)$ & 13.44 \\
\hline $\operatorname{Han}(2010)$ & Chinese & $1.24(1.01,1.52)$ & 6.08 \\
\hline Wen(2010) & Chinese & $1.15(0.96,1.38)$ & 7.71 \\
\hline $\operatorname{Liu}(2010)$ & Chinese & $1.22(1.05,1.41)$ & 11.68 \\
\hline Present study & Chinese & $1.17(1.03,1.32)$ & 16.50 \\
\hline \multicolumn{2}{|c|}{ Heterogeneity $P=0.430, \mathrm{I}$-squared $=1.2 \%$} & $1.13(1.07,1.19)$ & 100.00 \\
\hline & 0.49 & 2.04 & \\
\hline
\end{tabular}

Figure 1 Meta-analysis of the association between rs8050136 polymorphism and the risk of T2D in East Asians. To estimate the pooled effect size of SNP rs8050136 on T2D risk in East Asians, a meta-analysis including 10 published studies on the association between rs 8050136 polymorphism and T2D risk in East Asians and our present study was conducted. There was no heterogeneity of ORs across studies ( $p=0.430$ and $I^{2}=1.2 \%$ ). The pooled OR for SNP rs8050136 and the risk of T2D was significant (pooled $\mathrm{OR}=1.13,95 \% \mathrm{Cl}=1.07-1.19$ ) in East Asians. 


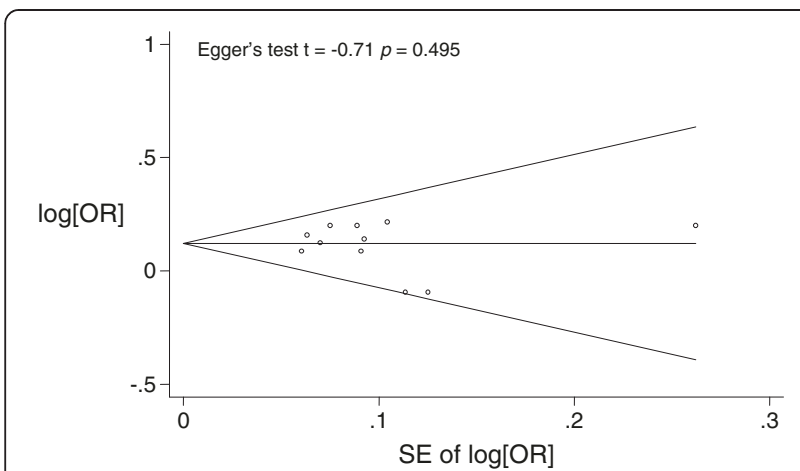

Figure 2 Funnel plot analysis to detect the publication bias in East Asians. The funnel plot was symmetrical and the result from Egger's test was non-significant ( $t=-0.71, p=0.495)$.

consistent with those of the earlier study that showed the association of rs8050136 with T2D risk was mediated through BMI among Europeans [6].

The SNP rs8050136 is mapped to the intron 1 of FTO gene on chromosome 16. The exact function of the gene product of FTO is not yet understood and how the polymorphism affects the risk of T2D is unclear. Based on sequence homology, FTO gene is predicted to encode a 2-oxoglutarate-dependent demethylase enzyme, which affects nucleic acid demethylation [20]. This gene may be critical in epigenetic regulation of the progress of T2D. Recently, Bravard et al. found a significant increase of FTO mRNA and protein in skeletal muscle of T2D patients, suggesting that FTO may involve in T2D pathogenesis through oxidative metabolism, lipogenesis and oxidative stress in muscle defects [21].

The limitation of this case-control study was that most of the T2D cases were diagnosed before the surveys and therefore, their BMI may not be a perfect measure of adiposity, particularly in lean individuals and in East Asians who usually have more abdominal fat and less muscle mass than Caucasians. Although we adjusted BMI for adiposity in detecting the association of FTO polymorphism with T2D risk, we cannot rule out the possibility of residual confounding of obesity, because the alternative measures (such as DEXA fat mass) of adiposity were not available in this study. More alternative measures of adiposity need to be considered in future studies.

\section{Conclusions}

In summary, we evaluated the association of FTO rs8050136 polymorphism with the risk of T2D in a large case-control study and 2 meta-analyses and confirmed that the $A$ allele was significantly associated with an increased risk of T2D in East Asians. Further studies are warranted to clarify the potentially biological mechanisms of FTO rs8050136 polymorphism in T2D pathogenesis.

\section{Methods}

\section{Study subjects}

All subjects were genetically unrelated ethnic Han Chinese and the study population was previously described [22,23]. In brief, 2,925 T2D cases and 3,281 controls were recruited from 2 community-based chronic non-communicable disease surveys in Jiangsu province, from 2004 to 2008. Subjects were considered to have T2D if they had a history of T2D or if their fasting glucose was $7.0 \mathrm{mmol} / \mathrm{l}$ or higher. Those without history of diabetes, hypertension, coronary heart disease, stroke, cancer and with fasting glucose $<5.6 \mathrm{mmol} / \mathrm{l}$ were selected as controls from the same population and frequency-matched to the cases by age, sex and residential area. All participants were interviewed by trained interviewers to obtain information on demographic data, smoking, alcohol drinking, family history, physical activity and disease history using standard questionnaires. At the same time, anthropometrical measurements were performed. A $5 \mathrm{ml}$ blood sample was collected from each subject after fasting for more than 8 hours. FBG and lipid levels, including TC, TG, and HDL-C were detected in standard methods. According to the criteria proposed by the Working Group on Obesity in China, we defined overweight as $24 \mathrm{~kg} / \mathrm{m}^{2} \leq \mathrm{BMI}<28 \mathrm{~kg} / \mathrm{m}^{2}$, and obesity as BMI $\geq 28 \mathrm{~kg} / \mathrm{m}^{2}$ [24]. The distributions of demographic and clinical characteristics of the T2D cases and controls were summarized in (Additional file 1: Table S1). This study was approved by the institutional review board of Nanjing Medical University. Written informed consent was obtained from each participant.

\section{Genotyping assay}

Genomic DNA was isolated from leukocyte pellets of venous blood by proteinase $\mathrm{K}$ digestion, followed by phenolchloroform extraction. TaqMan OpenArray Genotyping System (Life Technologies, Carlsbad, CA, USA) and the iPLEX Sequenom MassARRAY platform (Sequenom, Inc., San Diego, CA, USA) were used to perform genotyping. Genotype was successfully detected in 2,898 cases and 3,262 controls, with the call rate being $99.2 \%$. Genotyping was performed by technicians without knowing the statuses of T2D cases or controls. Two blank controls in each plate were used for quality control. 96 randomly selected duplicated samples were examined on two platforms and the concordant rate was $100 \%$.

\section{Meta-analysis}

We searched all case-control studies on the association between FTO gene rs8050136 polymorphism and T2D risk in East Asian populations. Eligible studies, published in English, up to August, 2012, were identified by using the search terms "FTO and polymorphism and type 2 
diabetes" in PubMed. Studies that were not conducted in East Asians were excluded in manual. ORs and 95\% CIs were calculated in additive model after adjustment in logistic regression. Cochran's $X^{2}$-based Q-statistic test was performed to assess the heterogeneity among the included studies. The combined OR was calculated using the Mantel-Haenszel method in fixed-effect model with 95\% CI in Woolf's method as there was no significant heterogeneity. Publication bias was evaluated with Egger's $t$ test.

\section{Statistical analyses}

The differences in demographic variables, selected variables, and frequencies of the genotypes between cases and controls were evaluated by using the Student's $t$-test for continuous variables and the $X^{2}$ - test for categorical variables. The Hardy-Weinberg equilibrium was tested by a goodness-of-fit $\chi^{2}$ - test in controls. The association between SNP and T2D risk was estimated by computing the ORs and 95\% CIs using unconditional logistic regression analysis after adjustment for age, sex and BMI. Heterogeneity test for stratified analyses of the selected variables was conducted with the $\chi^{2}$-based $Q$ test. Multivariate linear regression analyses were performed to test the correlation between the genotypes and quantitative BMI trait after adjustment for age and sex. The statistical power was calculated by PS (power and sample size calculation) 3.0.2 software. All statistical analyses were performed by using STATA version 11.0 (StataCorp LP, College Station, TX, USA).

\section{Additional files}

Additional file 1: Table S1. General characteristics of type 2 diabetes cases and controls. This table shows the characteristics of the study population. No significant differences were observed in the distributions of sex, smoking and drinking status. Type 2 diabetes cases were older than controls and had significantly higher levels of body mass index, fasting blood glucose, triglyceride, total cholesterol, blood pressure and significantly lower level of high-density lipoprotein cholesterol.

Additional file 2: Table S2. Published studies on the association between rs8050136 polymorphism and the risk of type 2 diabetes in East Asians. The table displays minor allele frequencies (MAFs), sample sizes, adjusted odds ratios (ORs) and 95\% confidence intervals (Cls), p-values, populations, journals, authors and published year of the 10 published studies among East Asian populations. They were included in the metaanalyses together with the present study.

Additional file 3: Figure S1. Meta-analysis of the association of rs8050136 polymorphism with the risk of type 2 diabetes in Han Chinese. The figure shows the results of the meta-analysis covering 6 reported studies in Chinese Han populations and our present study.

Additional file 4: Figure S2. Funnel plot analysis to detect the publication bias in Chinese Han populations. The figure shows the results of the funnel plot analysis to address the potential publication bias about the 7 studies conducted among Chinese Han populations.

\section{Abbreviations}

GWAS: Genome-wide association study; FTO: Fat mass and obesityassociated gene; T2D: Type 2 diabetes; BMI: Body mass index; OR: Odds ratio; 95\% Cl: 95\% confidence interval; SNP: Single nucleotide polymorphism; LD: Linkage disequilibrium; FBG: Fasting blood glucose; TC: Total cholesterol; TG: Triglyceride; HDL-C: High-density lipoproteincholesterol; HWE: Hardy-weinberg equilibrium; MAF: Minor allele frequency.

\section{Competing interests}

The authors declare that they have no competing interests.

\section{Authors' contributions}

YQ carried out the molecular genetic studies, participated in the genotype detection and statistical analysis, drafted the manuscript and is the corresponding author. SL and FL performed the experiments and analyzed the data. $\mathrm{HL}$ participated in the genotype detection and the statistical analysis. MD and $\mathrm{YL}$ participated in the field investigation. JD, JG and $\mathrm{YL}$ participated in the genotype detection. GJ and JD participated in the design and the data analysis. ZH involved in the design and coordination. HS conceived the study, edited the manuscript, and is the corresponding author. All authors read and approved the final manuscript.

\section{Acknowledgements}

This work was supported by the National Natural Science Foundation of China $(81072379,81102180)$, the Ministry of Health Research Program (WKJ2010-2-032), Wuxi Science \& Technology Research Program (CSE01016), and the Priority Academic Program for the Development of Jiangsu Higher Education Institutions (Public Health and Preventive Medicine).

\section{Author details}

${ }^{1}$ Department of Chronic Non-communicable Disease Control, Wuxi Center for Disease Control and Prevention, Wuxi, China. ${ }^{2}$ Department of Epidemiology and Biostatistics, MOE Key Laboratory of Modern Toxicology, School of Public Health, Nanjing Medical University, Nanjing, China. ${ }^{3}$ Department of Chronic Non-communicable Disease Control, Zhejiang Provincial Center for Disease Control and Prevention, Hangzhou, China. ${ }^{4}$ Department of Cancer Prevention and Treatment, Zhejiang Cancer Hospital, Hangzhou, China. ${ }^{5}$ State Key Laboratory of Reproductive Medicine, Nanjing Medical University, Nanjing, China.

Received: 3 April 2013 Accepted: 16 September 2013

Published: 22 September 2013

\section{References}

1. Narayan KM, Boyle JP, Geiss LS, Saaddine JB, Thompson TJ: Impact of recent increase in incidence on future diabetes burden: US, 2005-2050 Diabetes Care 2006, 29(9):2114-2116.

2. Chan JC, Malik V, Jia W, Kadowaki T, Yajnik CS, Yoon KH, Hu FB: Diabetes in Asia: epidemiology, risk factors, and pathophysiology. JAMA 2009, 301(20):2129-2140.

3. Yang W, Lu J, Weng J, Jia W, Ji L, Xiao J, Shan Z, Liu J, Tian H, Ji Q, Zhu D, Ge J, Lin L, Chen L, Guo X, Zhao Z, Li Q, Zhou Z, Shan G, He J, China National Diabetes and Metabolic Disorders Study Group: Prevalence of diabetes among men and women in China. N Engl J Med 2010, 362(12):1090-1101.

4. Stumvoll M, Goldstein BJ, van Haeften TW: Type 2 diabetes: principles of pathogenesis and therapy. Lancet 2005, 365(9467):1333-1346.

5. Scott LJ, Mohlke KL, Bonnycastle LL, Willer CJ, Li Y, Duren WL, Erdos MR, Stringham HM, Chines PS, Jackson AU, Prokunina-Olsson L, Ding CJ, Swift AJ, Narisu N, Hu T, Pruim R, Xiao R, Li XY, Conneely KN, Riebow NL, Sprau AG, Tong M, White PP, Hetrick KN, Barnhart MW, Bark CW, Goldstein JL, Watkins L, Xiang F, Saramies J, et al: A genome-wide association study of type 2 diabetes in Finns detects multiple susceptibility variants. Science 2007, 316(5829):1341-1345.

6. Zeggini E, Weedon MN, Lindgren CM, Frayling TM, Elliott KS, Lango H, Timpson NJ, Perry JR, Rayner NW, Freathy RM, Barrett JC, Shields B, Morris AP, Ellard S, Groves CJ, Harries LW, Marchini JL, Owen KR, Knight B, Cardon LR, Walker M, Hitman GA, Morris AD, Doney AS, Wellcome Trust Case Control Consortium (WTCCC), McCarthy MI, Hattersley AT: Replication of genome-wide association signals in UK samples reveals risk loci for type 2 diabetes. Science 2007, 316(5829):1336-1341.

7. Frayling TM, Timpson NJ, Weedon MN, Zeggini E, Freathy RM, Lindgren CM, Perry JR, Elliott KS, Lango H, Rayner NW, Shields B, Harries LW, Barrett JC, 
Ellard S, Groves CJ, Knight B, Patch AM, Ness AR, Ebrahim S, Lawlor DA, Ring SM, Ben-Shlomo Y, Jarvelin MR, Sovio U, Bennett AJ, Melzer D, Ferrucci L, Loos RJ, Barroso I, Wareham NJ, et al: A common variant in the FTO gene is associated with body mass index and predisposes to childhood and adult obesity. Science 2007, 316(5826):889-894.

8. Horikoshi M, Hara K, Ito C, Shojima N, Nagai R, Ueki K, Froguel P, Kadowaki T: Variations in the HHEX gene are associated with increased risk of type 2 diabetes in the Japanese population. Diabetologia 2007, 50(12):2461-2466

9. Ng MC, Park KS, Oh B, Tam CH, Cho YM, Shin HD, Lam VK, Ma RC, So WY, Cho YS, Kim HL, Lee HK, Chan JC, Cho NH: Implication of genetic variants near TCF7L2, SLC30A8, HHEX, CDKAL1, CDKN2A/B, IGF2BP2, and FTO in type 2 diabetes and obesity in 6,719 Asians. Diabetes 2008, 57(8):2226-2233.

10. Hu C, Zhang R, Wang C, Wang J, Ma X, Lu J, Qin W, Hou X, Wang C, Bao Y, Xiang K, Jia W: PPARG, KCNJ11, CDKAL1, CDKN2A-CDKN2B, IDE-KIF11 -HHEX, IGF2BP2 and SLC30A8 are associated with type 2 diabetes in a Chinese population. PLoS One 2009, 4(10):e7643.

11. Han X, Luo Y, Ren Q, Zhang X, Wang F, Sun X, Zhou X, Ji L: Implication of genetic variants near SLC30A8, HHEX, CDKAL1, CDKN2A/B, IGF2BP2, FTO, TCF2, KCNQ1, and WFS1 in type 2 diabetes in a Chinese population. BMC Med Gene 2010, 11:81.

12. Omori S, Tanaka Y, Takahashi A, Hirose H, Kashiwagi A, Kaku K, Kawamori R, Nakamura Y, Maeda S: Association of CDKAL1, IGF2BP2, CDKN2A/B, HHEX, SLC30A8, and KCNJ11 with susceptibility to type 2 diabetes in a Japanese population. Diabetes 2008, 57(3):791-795.

13. Li H, Wu Y, Loos RJ, Hu FB, Liu Y, Wang J, Yu Z, Lin X: Variants in the fat mass- and obesity-associated (FTO) gene are not associated with obesity in a Chinese Han population. Diabetes 2008, 57(1):264-268.

14. Liu Y, Liu Z, Song Y, Zhou D, Zhang D, Zhao T, Chen Z, Yu L, Yang Y, Feng G, Li J, Zhang J, Liu S, Zhang Z, He L, Xu H: Meta-analysis added power to identify variants in FTO associated with type 2 diabetes and obesity in the Asian population. Obesity (Silver Spring) 2010, 18(8):1619-1624.

15. Lee YH, Kang ES, Kim SH, Han SJ, Kim CH, Kim HJ, Ahn CW, Cha BS, Nam M, Nam CM, Lee HC: Association between polymorphisms in SLC30A8, HHEX, CDKN2A/B, IGF2BP2, FTO, WFS1, CDKAL1, KCNQ1 and type 2 diabetes in the Korean population. J Hum Genet 2008, 53(11-12):991-998.

16. Song Y, You NC, Hsu YH, Howard BV, Langer RD, Manson JE, Nathan L, Niu T, Tinker FL, Liu S: FTO polymorphisms are associated with obesity but not diabetes risk in postmenopausal women. Obesity (Silver Spring) 2008, 16(11):2472-2480.

17. Wen J, Rönn T, Olsson A, Yang Z, Lu B, Du Y, Groop L, Ling C, Hu R: Investigation of type 2 diabetes risk alleles support CDKN2A/B, CDKAL1, and TCF7L2 as susceptibility genes in a Han Chinese cohort. PLoS One 2010, 5(2):e9153.

18. Li H, Kilpeläinen TO, Liu C, Zhu J, Liu Y, Hu C, Yang Z, Zhang W, Bao W, Cha S, Wu Y, Yang T, Sekine A, Choi BY, Yajnik CS, Zhou D, Takeuchi F, Yamamoto K, Chan JC, Mani KR, Been LF, Imamura M, Nakashima E, Lee N, Fujisawa T, Karasawa S, Wen W, Joglekar CV, Lu W, Chang Y, et al: Association of genetic variation in FTO with risk of obesity and type 2 diabetes with data from 96,551 East and South Asians. Diabetologia 2012, 55(4):981-995.

19. Hertel JK, Johansson S, Sonestedt E, Jonsson A, Lie RT, Platou CG, Nilsson PM, Rukh G, Midthjell K, Hveem K, Melander O, Groop L, Lyssenko V, Molven A, Orho-Melander M, Niølstad PR: FTO, type 2 diabetes, and weight gain throughout adult life: a meta-analysis of 41,504 subjects from the Scandinavian HUNT, MDC, and MPP studies. Diabetes 2011, 60(5):1637-1644

20. Gerken T, Girard CA, Tung YC, Webby CJ, Saudek V, Hewitson KS, Yeo GS, McDonough MA, Cunliffe S, McNeill LA, Galvanovskis J, Rorsman P, Robins P, Prieur X, Coll AP, Ma M, Jovanovic Z, Faroogi IS, Sedgwick B, Barroso I, Lindahl T, Ponting CP, Ashcroft FM, O'Rahilly S, Schofield CJ: The obesityassociated FTO gene encodes a 2-oxoglutarate-dependent nucleic acid demethylase. Science 2007, 318(5855):1469-1472.

21. Bravard A, Lefai E, Meugnier E, Pesenti S, Disse E, Vouillarmet J, Peretti N, Rabasa-Lhoret R, Laville M, Vidal H, Rieusset J: FTO is increased in muscle during type 2 diabetes, and its overexpression in myotubes alters insulin signaling, enhances lipogenesis and ROS production, and induces mitochondrial dysfunction. Diabetes 2011, 60(1):258-268

22. Lu F, Qian Y, Li H, Dong M, Lin Y, Du J, Lin Y, Chen J, Shen C, Jin G, Dai J, Hu Z, Shen H: Genetic variants on chromosome 6p21.1 and 6p22.3 are associated with type 2 diabetes risk: a case-control study in Han Chinese. J Hum Genet 2012, 57(5):320-325.
23. Qian Y, Lu F, Dong M, Lin Y, Li H, Chen J, Shen C, Jin G, Hu Z, Shen H: Genetic variants of IDE-KIF11-HHEX at 10q23.33 associated with type 2 diabetes risk: a fine-mapping study in Chinese population. PLoS One 2012, 7(4):e35060.

24. Zhou BF, Cooperative Meta-Analysis Group of the Working Group on Obesity in China: Predictive values of body mass index and waist circumference for risk factors of certain related diseases in Chinese adults--study on optimal cut-off points of body mass index and waist circumference in Chinese adults. Biomed Environ Sci 2002, 15(1):83-96.

doi:10.1186/1471-2156-14-86

Cite this article as: Qian et al: Genetic variant in fat mass and obesityassociated gene associated with type 2 diabetes risk in Han Chinese. BMC Genetics 2013 14:86.

\section{Submit your next manuscript to BioMed Central and take full advantage of:}

- Convenient online submission

- Thorough peer review

- No space constraints or color figure charges

- Immediate publication on acceptance

- Inclusion in PubMed, CAS, Scopus and Google Scholar

- Research which is freely available for redistribution 